\title{
Comparative haemodynamic studies of resting and active skeletal muscle in anaesthetised rats: role of nitric oxide
}

\author{
Csilla Hably ${ }^{1}$, J. Vág², J. Bartha1 \\ ${ }^{1}$ Department of Physiology and \\ ${ }^{2}$ Clinic of Conservative Dentistry, Semmelweis University of Medicine, Budapest, Hungary
}

Received: May 24, 2001

Accepted: July 15, 2001

\begin{abstract}
Our previous studies have indicated that nitric oxide takes part in the basal regulation of vascular tone in skeletal muscle. The purpose of this study was to investigate whether nitric oxide has a role in the active hyperaemic response of a working muscle in a resting subject.

Haemodynamic effects of nitric oxide synthase (NOS) inhibition (L-NAME, $10 \mathrm{mg} / \mathrm{kg} / 30$ min iv. infusion) were determined simultaneously in the resting $\mathrm{m}$. quadriceps femoris and in the working (breathing) $\mathrm{m}$. rectus abdominis in anaesthetised rats $\left({ }^{86} \mathrm{Rb}\right.$ accumulation technique).

L-NAME increased blood pressure and total peripheral resistance (TPR) while it decreased cardiac output. Blood flow (BF) decreased and vascular resistance (VR) increased both in resting (BF: $8.91 \pm 1.97 \rightarrow 5.92 \pm 2.59 \mathrm{ml} / \mathrm{min} / 100 \mathrm{~g}, \mathrm{p}<0.05$; VR: $106 \pm 29.9 \rightarrow 212 \pm 113 \mathrm{R}$, $\mathrm{p}<0.01$ ) and working (BF: $17.0 \pm 4.78 \rightarrow 6.93 \pm 2.15 \quad \mathrm{ml} / \mathrm{min} / 100 \mathrm{~g}, \quad \mathrm{p}<0.001$; VR: $57.0 \pm 18.5 \rightarrow 160 \pm 56.7 \mathrm{R}, \mathrm{p}<0.01)$ muscle following NOS inhibition, but the percentile change of BF was higher in the working muscle $(59 \%)$ than in the resting one $(34 \%, \mathrm{p}<0.001)$. There was a positive correlation between the cardiac output and the blood flow of the resting muscle with or without L-NAME administration, but blood flow of the working muscle failed to have any correlation with the cardiac output in control animals. However, L-NAME administration decreased both the cardiac output and the blood flow and similarly to the resting muscle a positive correlation was found.

In conclusion, the haemodynamic effects of NOS inhibition are higher in working muscle than in the resting one: the nitric oxide may have important role in vasodilatation during muscle activity.
\end{abstract}

Correspondence should be addressed to

Csilla Hably

Department of Physiology, Semmelweis University of Medicine

H-1444 Budapest 8., P.O.Box 259, Puskin u. 9, Hungary

Phone: 36-1-266-2755/4057, Fax: 36-1-266-7480

This work was supported by the National Scientific Research Fund (OTKA, T-023383),

Hungarian Kidney Foundation and the Hungarian Nephrological Society. 
Keywords: muscle blood flow, resting and working skeletal muscle, nitric oxide, vascular tone, blood pressure, total peripheral resistance, cardiac output, L-NAME

The role of nitric oxide in the basal regulation of vascular tone has been observed almost in all of the organs $(3)$. In vivo $(3,10,11)$ and in vitro $(6,16)$ experiments have proved that the vascular endothelium in resting skeletal muscle produces nitric oxide. Nitric oxide counterbalances the effect of sympathetic nervous system playing an important role in the basal regulation of vasomotor tone in skeletal muscle, too $(1,18)$.

Blood flow in active muscle increases dramatically during exercise. This increase in blood flow is permitted by relaxation of smooth muscle in the vasculature of muscle tissue. Traditional explanation for the hyperaemia which accompanies exercise has involved the "metabolic theory" of vasodilatation. According to this theory the contraction of the active muscle gives rise to metabolic products which dilate vessels bathing in interstitial fluid. Although these metabolites were identified, this theory does not explain the magnitude of hyperaemia observed in active skeletal muscle. To obtain a 10-20 fold increase of muscle blood flow during exercise the dilatation of arterioles and "feed" arteries is also must have taken place (1). These vessels lying outside the tissue parenchyma are not subjected to changes in the interstitial milieu. According to Green and coworkers the coordinated dilatation of resistance vessels could be explained by a retrograde signal from the microvessels to the arterioles and feed arteries (1).

The way of the retrograde signal could be the endothelium. Endothelial cells are in contact with the blood and the vascular smooth muscle, respectively, in this way they may be able to transduce the rheological and humoral changes of blood into vasoactive signals (1).

In vitro findings demonstrated that in gracilis muscle arterioles in response to increases in flow (shear stress) nitric oxide released (6), so nitric oxide could be one of the signals of the retrograde vasodilatation. In present experiments the role of nitric oxide in active hyperaemia was investigated via comparing the blood flow of a working and a resting skeletal muscle in a resting animal. In our experiment the m. quadriceps femoris was chosen as a resting muscle, and the active one was the m. rectus abdominis, which takes part in the spontaneous breathing in the anaesthetised animal.

\section{Materials and Methods}

Experiments were conducted in Wistar rats (200-240 g). Animals had been kept on standard chow and tap water ad libitum until experiments started.

Haemodynamic investigations were carried out in anaesthesia (sodium pentobarbital, $60 \mathrm{mg} / \mathrm{kg}$, i.p.). A cannula was inserted into the right atrium via the right external jugular vein, the left common carotid artery and a tail vein were also 
cannulated. Blood pressure was measured in the left common carotid artery. It was continuously monitored with a Statham pressure transducer and recorded by an electromanometer (Experimetria Ltd).

Following the stabilisation of blood pressure nitric oxide synthase (NOS) inhibitor N $\omega$-nitro-L-arginine methyl esther (L-NAME, $10 \mathrm{mg} / \mathrm{kg} / 30 \mathrm{~min}$ ) was infused intravenously. Control animals were given the same amount of solvent (saline). Cardiac output was determined by the by Stewart-Hamilton principle (15), blood flow of the resting $\mathrm{m}$. quadriceps femoris and the active $\mathrm{m}$. rectus abdominis was measured by Sapirstein's method (13) simultaneously, applying ${ }^{86} \mathrm{Rb}$ as indicator. Details of these techniques are available elsewhere (2). Total peripheral resistance (TPR) and vascular resistance in the muscle were calculated as the quotient of the mean arterial blood pressure and the cardiac output (TPR) or blood flow of the given tissue (vascular resistance in the muscle). The tissue fraction of cardiac output was determined as the ratio of blood flow of $1 \mathrm{~g}$ muscle tissue and the cardiac output for $100 \mathrm{~g} \mathrm{b.m}$. This ratio shows, how many per cent of cardiac output flows through $1 \mathrm{~g}$ resting or working muscle during one minute.

\section{Statistics}

All values are presented as mean \pm SD. Two-way ANOVA was used to evaluate the effect of activity and NOS inhibition and to test the relationship between them. Post hoc comparisons were made using a modified $t$-test. To determine the relationship between cardiac output and tissue blood flow regression analysis was made. The acceptable level of significance was $\mathrm{p}<0.05$.

\section{Results}

Systemic haemodynamic parameters (Table I)

NOS inhibition increased the blood pressure by $12 \%$ and decreased the cardiac output by $43 \%$. The total peripheral resistance (TPR) increased by $98 \%$ after L-NAME administration, and in spite of the low cardiac output this extreme vasoconstriction resulted in an elevated blood pressure. 


\section{Table I}

Systemic haemodynamic parameters in rats with or without acute nitric oxide synthase inhibition ( $\bar{x} \pm$ S.D.)

\begin{tabular}{lcc}
\hline & Control, $\mathrm{n}=10$ & L-NAME, $\mathrm{n}=10$ \\
\hline Blood pressure, $\mathrm{mm} \mathrm{Hg}$ & $149 \pm 13.1$ & $167 \pm 6.21^{* *}$ \\
Cardiac output, $\mathrm{ml} / \mathrm{min} / 100 \mathrm{~g}$ b.m. & $34.5 \pm 6.75$ & $19.6 \pm 4.61^{* * *}$ \\
TPR, R/kg & $27.1 \pm 7.36$ & $53.7 \pm 12.7^{* * *}$ \\
\hline
\end{tabular}

n: number of experiments

Significance: L-NAME vs. Control: ** $\mathrm{p}<0.01$, *** $\mathrm{p}<0.001$

TPR: total peripheral resistance

$\mathrm{R}: \mathrm{mm} \mathrm{Hg} \cdot \mathrm{ml}^{-1} \cdot \mathrm{s} \cdot \mathrm{kg}^{-1}$

\section{Haemodynamic parameters of the resting and working muscle (Table II)}

In control rats the blood flow of the working muscle is twofold compared to the resting one $(p<0.001)$, and the vascular resistance is the half than of the resting value $(\mathrm{p}<0.05)$. In spite of the fact that the contraction of the rectus abdominis muscle in a

\section{Table II}

Haemodynamic parameters of resting and working muscle in rats with or without acute nitric oxide synthase inhibition $(\bar{x} \pm$ S.D. $)$

\begin{tabular}{|c|c|c|c|c|c|}
\hline & \multicolumn{2}{|c|}{$\begin{array}{l}\text { M. quadriceps femoris } \\
\text { (resting muscle) } \\
n=10\end{array}$} & & \multicolumn{2}{|c|}{$\begin{array}{l}\text { M. rectus abdominis } \\
\text { (working muscle) } \\
n=10\end{array}$} \\
\hline & Control & L-NAME & & Control & L-NAME \\
\hline $\begin{array}{l}\text { Blood flow, } \\
\mathrm{ml} / \mathrm{min} / 100 \mathrm{~g} \text { tissue }\end{array}$ & $8.91 \pm 1.97$ & $5.92 \pm 2.59 *$ & $\S \S \S$ & $17.0 \pm 4.78$ & $6.93 \pm 2.15^{* * *}$ \\
\hline $\begin{array}{l}\text { Vascular resistance, } \\
\mathrm{R} / \mathrm{kg}\end{array}$ & $106 \pm 29.9$ & $212 \pm 113^{* *}$ & & $57.0 \pm 18.5$ & $160 \pm 56.7^{* *}$ \\
\hline $\begin{array}{l}\text { Tissue fraction } \\
\text { of cardiac output, \% }\end{array}$ & $0.13 \pm 0.01$ & $0.16 \pm 0.05$ & $\S \S$ & $0.25 \pm 0.07$ & $0.19 \pm 0.03^{*}$ \\
\hline
\end{tabular}

$\mathrm{n}$ : number of experiments

$\mathrm{R}: \mathrm{mm} \mathrm{Hg} \cdot \mathrm{ml}^{-1} \cdot \mathrm{s}^{\cdot} \mathrm{kg}^{-1}$

$\%$ : ratio of blood flow of $1 \mathrm{~g}$ muscle tissue and the cardiac output for $100 \mathrm{~g} \mathrm{~b} . \mathrm{m}$.

Significance: L-NAME vs. control $* \mathrm{p}<0.05, * * \mathrm{p}<0.01, * * * \mathrm{p}<0.001$

ANOVA on muscle activity $\S \S p<0.01, \S \S \S \mathrm{p}<0.001$ 
resting animal during eupnoe is not extreme, the tissue fraction of the cardiac output in working muscle is twice as high as that in the resting one $(\mathrm{p}<0.001)$.

NOS inhibition decreased blood flow and increased vascular resistance both in resting and working skeletal muscle. However, the magnitude of changes proved to be different: while in working muscle the decrease of blood flow was $-59 \%$, the increase of vascular resistance $+180 \%$, in resting one changes only as high as $-33 \%$ and $+100 \%$ were registered, respectively.

This difference shows not only the role of nitric oxide in the control of vascular tone in resting muscle but also it's extra role in blood flow regulation during active hyperaemia.

L-NAME did not significantly alter the tissue fraction of cardiac output in resting muscle. It means that the decrease of blood flow in $\mathrm{m}$. quadriceps femoris is in a direct relation to the decrease of cardiac output. However, in the working muscle NOS inhibition resulted in a significant decrease of the tissue fraction of cardiac output: the decrease of the blood flow in the working muscle is higher, than that in the resting one. Accordingly, without NOS inhibition in the working muscle more nitric oxide releases than in the resting one.

To clear up the relationship between the cardiac output and the muscle blood flow regression analysis was carried out. The blood flow values of the resting muscle were plotted against the cardiac output measured in control (empty circles) and in L-NAME treated (dark circles) rats (Fig. 1). A positive correlation was found between the blood flow of the resting muscle and the cardiac output both in control and in NOS inhibited animals: the higher the cardiac output of a resting animal the higher the blood flow of the resting skeletal muscle. The slopes of the two lines does not differ from each other: L-NAME does not alter the relationship between the cardiac output and blood flow of the resting muscle.

The relationship of cardiac output and blood flow in the active muscle (Fig. 2) is very different from those in the resting muscle. In control animals there is no correlation between the cardiac output and the blood flow of the working muscle: in a resting animal the blood flow of the active muscle does not depend on the cardiac output either. However, in L-NAME treated rats both cardiac output and muscle blood flow decreases and similarly to the resting muscle a positive correlation was found. That proves again that in working muscle nitric oxide has important role in cardiac output-independent increase of blood flow. 


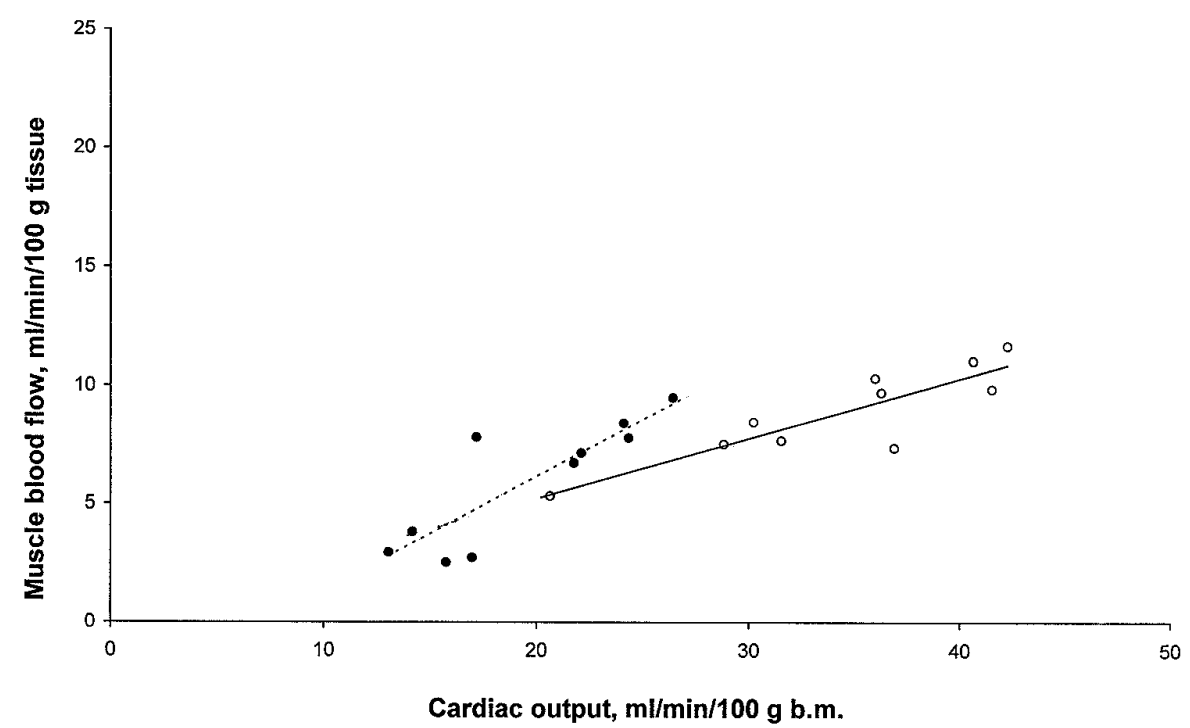

Fig. 1. Relationship of cardiac output and blood flow of the resting muscle (m. quadriceps femoris) in control (- $\mathrm{O} \mathrm{y}=0.255 \mathrm{x}+0.118, \mathrm{p}<0.001)$ and in L-NAME-treated $(-\cdots \mathrm{y}=0.483 \mathrm{x}-3.51, \mathrm{p}<0.01)$ anaesthetised rats

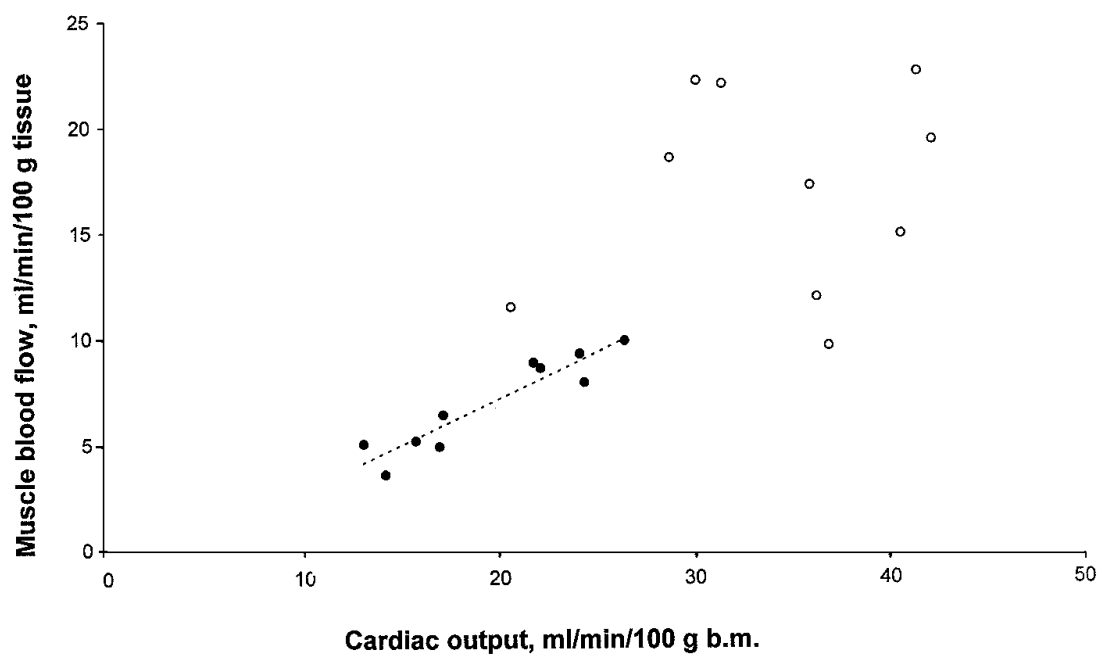

Fig. 2. Relationship of cardiac output and blood flow of the working muscle (m. rectus abdominis) in control (-— O r=0.4448, n. s.) and in L-NAME-treated (- - • $\mathrm{y}=0.440 \mathrm{x}-1.67, \mathrm{p}<0.001)$ anaesthetised rats 


\section{Discussion}

In present study the effect of NOS inhibition was compared in the resting and working muscle via investigating the blood flow simultaneously in the same animal at the same time. Rats were studied at complete rest (anaesthetised) breathing spontaneously. As working (active) muscle the m. rectus abdominis (taking part in the breathing, resting (inactive) muscle the $\mathrm{m}$. quadriceps femoris was used.

L-NAME resulted in an increase of TPR and blood pressure and a decrease of the cardiac output. These observations agree with previous results $(3,12,20)$ and prove the effectiveness of L-NAME at the dose applied.

In our experiments NOS inhibition decreased the blood flow and increased the vascular resistance both in resting and working muscle. Earlier the role of nitric oxide in the basal regulation of muscle blood flow was described $(3,6,11,17)$; our observations confirm these findings.

Role of nitric oxide in active hyperaemia was investigated under different circumstances. According to in vitro experiments endothelium-dependent vasodilatation is significantly enhanced in skeletal muscle arterioles originating from exercised rats (16). Active hyperaemia was blocked by inhibition of NOS in humans (4) and in animals $(7,19)$. The role of endothelium is supported by the observation that abnormalities of endothelial function may contribute to increased peripheral vasomotor tone during exercise in patients with congestive heart failure (5).

Although these investigations were done in very different circumstances the observations support our hypothesis demonstrating a role of nitric oxide in permitting increased muscle blood flow during exercise.

As nitric oxide releases from endothelial cells of different parts of the vascular system (arteries, arterioles, capillaries) the mechanism could be diverse. 1. Nitric oxide may have a role in metabolite-induced increase of blood flow of microcirculation. It was proved that the muscle vasodilatation induced by adenosine during systemic hypoxia is mainly dependent on nitric oxide synthesis (14). 2. On the other hand, elevated shear stress due to increased blood flow associated with exercise could be a stimulus for nitric oxide release in arteries and arterioles (8). In this way nitric oxide could mediate the retrograde vasodilation. 3. Even capillaries can take part in the active hyperaemia via release of nitric oxide. Nitric oxide may be released from capillary endothelial cells both in basal state and in response to the vasodilator bradykinin (9). The low basal levels of nitric oxide affect capillary blood flow by modulating local haemoconcentration and leukocyte adhesion, and higher levels of nitric oxide may cause a remote vasodilation to increase microvascular blood flow (9). 
Furthermore, not only endothelium-derived nitric oxide has a role in muscle vasodilation. Observations of Thomas et al. (18) suggest a specific role for neuronderived NOS (nNOS) in the local metabolic inhibition of $\alpha$-adrenergic vasoconstriction in active skeletal muscle.

The experimental circumstances were very different in the studies above. In an experiment exercise was simulated by stimulating the motor neuron of the muscle of interest $(7)$. In other ones $(4,8)$ muscle blood flow was investigated in awake subjects during exercise. In our present experiments simultaneous comparative studies of blood flow of a resting and a working muscle confirm that nitric oxide has an important role in the increase of muscle blood flow during muscle activity.

\section{REFERENCES}

1. Green, D.J., O’Driscoll, G., Blanksby, B.A., Taylor, R.R.: Control of skeletal muscle blood flow during dynamic exercise: contribution of endothelium-derived nitric oxide. Sports Med 21(2), 119-146 (1996).

2. Hably, Cs., Borsos, G., Bartha, J.: Different effects of naproxen on the organ blood flow in normo- and hypervolemic anesthetized rats. Acta Physiol Hung 82(3), 267-279 (1994).

3. Hably, Cs., Vág, J., Bartha, J.: Nitric oxide synthase inhibition increases vascular resistance in sodium and water loaded rats. Res Exp Med 198, 145-156 (1998).

4. Hickner, R.C., Fisher, J.S., Ehsani, A.A., Kohrt, W.M.: Role of nitric oxide in skeletal muscle blood flow at rest and during dynamic exercise in humans. Am J Physiol 273(1Pt2), H405-410 (1997).

5. Katz, S.D.: The role of endothelium-derived vasoactive substances in the pathophysiology of exercise intolerance in patients with congestive heart failure. Prog Cardiovasc Dis 38(1), 23-50 (1995).

6. Koller, A., Huang, A.: Impaired nitric oxide-mediated flow-induced dilation in arterioles of spontaneously hypertensive rats. Circ Res 74(3), 416-421 (1994).

7. McAllister, R.M., Hirai, T., Musch, T.I.: Contribution of endothelium-derived nitric oxide (EDNO) to the skeletal muscle blood flow response to exercise. Med Sci Sports Exerc 27(8), 1145-1151 (1995).

8. McAllister, R.M.: Endothelial-mediated control of coronary and skeletal muscle blood flow during exercise: introduction. Med Sci Sports Exerc 27(8), 1122-1124 (1995).

9. Mitchell, D., Tyml, K.: Nitric oxide release in rat skeletal muscle capillary. Am J Physiol 270(5Pt2), H1696-1703 (1996).

10. Nakamura, T., Prewitt, R.L.: Effect of $\mathrm{N}^{\mathrm{G}}$-monomethyl-L-arginine on arcade arterioles of rat spinotrapezius muscle. Am J Physiol 261, H46-52 (1991).

11. Quintero, E., Guth, P.H.: Renal failure increases gastric mucosal blood flow and acid secretion in rats: role of endothelium-derived nitric oxide. Am J Physiol 263(1Pt1), G75-80 (1992).

12. Rees, D.D., Palmer, R.M.J., Moncada, S.: Role of endothelium-derived nitric oxide in the regulation of blood pressure. Proc Natl Acad Sci USA 86, 3375-3378 (1989).

13. Sapirstein, L.: Regional blood flow by fractional distribution of indicators. Am J Physiol 193, 161-168 (1958).

14. Skinner, M.R., Marshall, J.M.: Studies on the roles of ATP, adenosine and nitric oxide in mediating muscle vasodilatation induced in the rat by acute systemic hypoxia. J Physiol Lond 495(Pt2), 553-560 (1996).

15. Stewart, N.G.: Researches on the circulation time and on the influences which effect it. IV. The output of the heart. J Physiol (Lond) 22, 159 (1898). 
16. Sun, D., Huang, A., Koller, A., Kaley, G.: Short-term daily exercise activity enhances endothelial NO synthesis in skeletal muscle arterioles of rats. J Appl Physiol 76(5), 2241-2247 (1994).

17. Sun, D., Messina, E.J., Koller, A., Wolin, M.S., Kaley, G.: Endothelium-dependent dilation to Larginine in isolated rat skeletal muscle arterioles. Am J Physiol 262(4Pt2), H1211-1216 (1992).

18. Thomas, G.D., Sander, M., Lau, K.S., Huang, P.L., Stull, J.T., Victor, R.G.: Impaired metabolic modulation of alpha-adrenergic vasoconstriction in dystrophin-deficient skeletal muscle. Proc Natl Acad Sci USA 95(25), 15090-15095 (1998).

19. Thomas, G.D., Victor, R.G.: Nitric oxide mediates contraction-induced attenuation of sympathetic vasoconstriction in rat skeletal muscle. J Physiol Lond 506(Pt3), 817-826 (1998).

20. Vág, J., Hably, Cs., Csabai, Zs., Tost, H., Bartha, J., Fazekas, Á.: Blood flow of the submandibular gland in sodium-depleted and loaded rats: effect of nitric oxide synthase inhibition. Res Exp Med 198, 101-108 (1998). 